\title{
Isotope Exchange by Ion Cyclotron Wall Conditioning on JET
}

T. Wauters ${ }^{\mathrm{a}^{*}}$, D. Douai ${ }^{\mathrm{b}}$, D. Kogut ${ }^{\mathrm{b}}$, A. Lyssoivan ${ }^{\mathrm{a}}$, S. Brezinsek ${ }^{\mathrm{c}}$, E. Belonohy $^{\mathrm{d}}, \mathrm{T}$.

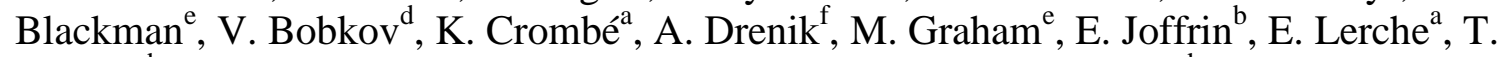
Loarer $^{\mathrm{b}}$, P.L. Lomas ${ }^{\mathrm{e}}$, M.-L. Mayoral ${ }^{\mathrm{e}}$, I. Monakhov ${ }^{\mathrm{e}}$, M. Oberkofler ${ }^{\mathrm{d}}$, V. Philipps ${ }^{\mathrm{c}}$, V. Plyusnin $^{\mathrm{g}}$, G. Sergienko ${ }^{\mathrm{c}}$, D. Van Eester ${ }^{\mathrm{a}}$ and JET EFDA Contributors*

JET-EFDA, Culham Science Centre, Abingdon, OX14 3DB, UK

${ }^{a}$ Laboratory for Plasma Physics, ERM/KMS, 1000 Brussels, Belgium, TEC partner

${ }^{b}$ CEA, IRFM, F-13108 St-Paul-Lez-Durance, France

${ }^{c}$ Forschungszentrum Jülich, Institut für Energie- und Klimaforschung Plasmaphysik, 52425

Jülich, Germany

${ }^{d}$ Max-Planck Institut für Plasmaphysik, 85748 Garching, Germany

${ }^{e} J E T-E F D A$, Culham Science Centre, Abingdon, OX14 3DB, UK

${ }^{f}$ Jožef Stefan Institute, 1000 Ljubljana, Slovenia

${ }^{g}$ IST, Instituto de Plasmas e Fusão nuclear, 1049-001 Lisboa, Portugal

See the Appendix of F. Romanelli et al., Proceedings of the 24th IAEA FEC 2012, San Diego

\begin{abstract}
The isotopic exchange efficiencies of JET Ion Cyclotron Wall Conditioning (ICWC) discharges produced at ITER half and full field conditions are compared for JET carbon (C) and ITER like wall (ILW). Besides an improved isotope exchange rate on the ILW providing cleaner plasma faster, the main advantage compared to $\mathrm{C}$-wall is a reduction of the ratio of retained discharge gas to removed fuel. Complementing experimental data with discharge modeling shows that long pulses with high $(\sim 240 \mathrm{~kW}$ coupled) ICRF power maximizes the wall isotope removal per ICWC pulse. In the pressure range 1 to $7.5 \times 10^{-3} \mathrm{~Pa}$, this removal reduces with increasing discharge pressure. As most of the wall-released isotopes are evacuated by vacuum pumps in the post discharge phase, duty cycle optimization studies for ICWC on JET-ILW need further consideration. The accessible reservoir by $\mathrm{H}_{2}$-ICWC at ITER half field conditions on the JET-ILW preloaded by $\mathrm{D}_{2}$ tokamak operation is estimated to be $7.3 \times 10^{22}$ hydrogenic atoms, and may be exchanged within $400 \mathrm{~s}$ of cumulated ICWC discharge time.
\end{abstract}

PACS: 52.40.Hf, 52.50.Qt, 52.55.Dy, 52.80.Pi

PSI-21 keywords: Discharge cleaning, JET, ILW, CFC, ICRF

*Corresponding author address: LPP-ERM/KMS, Association Euratom-Belgian State, 1000

Brussels, Belgium

*Corresponding author E-mail: t.wauters@fz-juelich.de

Presenting author: Tom Wauters

Presenting authore-mail: t.wauters@fz-juelich.de 


\section{Introduction}

Ion cyclotron wall conditioning (ICWC) is a well-studied discharge wall conditioning technique for fusion devices applied in the presence of nominal toroidal magnetic fields $[1,2,3]$. Recent experiments on JET assessed ICWC for isotope exchange on the ITER-like wall (ILW) equipped with a Be main chamber and a W divertor ([4]) and compared the efficiency to earlier experiments with the JET-CFC wall. This contribution presents an overview of these experiments with focus on (i) ICWC discharge characterization both at ITER full field and half field scenario, (ii) investigating the accessible fuel reservoir by ICWC from particle balance analysis on JET-C and JET-ILW, as well as (iii) optimizing the fuel removal efficiency. Long-term fuel retention with JET-ILW was already shown to be at least ten times lower than in JET-C whereas the accessible reservoir near the surface, reflected in the short-term retention, is expected to be in the same range [5].

Isotope exchange conditioning discharges aim at replacing hydrogen isotopes stored in the near surface $(<100 \mathrm{~nm})$ to control the plasma isotopic ratio of subsequent tokamak discharges and may be used on ITER to recover tritium. The isotopic exchange efficiency is expressed as the rate at which a technique can change the isotopic ratio of the walls and the total extra retention it causes. Isotopic exchange experiments on JET are especially motivated by the need for assessing the exchange efficiency on the JET-ILW as well as JET's unique possibility to simulate $\mathrm{D}_{2}$-ICWC in ITER full field conditions.

\section{Experimental setup}

The use of ICWC during the non-active operation phase (H plasmas) and active phase (D and D:T plasmas) of ITER implies fixed toroidal field values of respectively half $\left(\mathrm{B}_{0}=2.65 \mathrm{~T}\right)$ and full (5.3T) nominal magnetic field. Operating the JET antennas at $25 \mathrm{MHz}$ with toroidal field values of respectively $\mathrm{B}_{0}=3.3 \mathrm{~T}$ and $1.65 \mathrm{~T}$ simulates on JET the ITER full $(5.3 \mathrm{~T} / 40 \mathrm{MHz})$ and half $(2.65 \mathrm{~T} / 40 \mathrm{MHz})$ field case with on axis location of fundamental $\mathrm{D}^{+}\left(\right.$resp. $\left.\mathrm{H}^{+}\right)$resonance 
layer. A small vertical magnetic field with field lines following the curvature of the inner and outer main chamber plasma facing components (PFC) is applied with amplitude optimized for maximal poloidal homogeneity $\left(\mathrm{B}_{\mathrm{V}} / \mathrm{B}_{0}=8 \times 10^{-3}\right)[6]$.

Three separate JET experiments were conducted: (i) ITER full field $\mathrm{D}_{2}-\mathrm{ICWC}$ with cryopumping on $\mathrm{H}_{2}$-GDC preloaded C-wall, (ii) ITER full field $\mathrm{D}_{2}-\mathrm{ICWC}^{\mathrm{II}}$ with turbo-pumping on $\mathrm{H}_{2}$-GDC preloaded ILW and (iii) ITER half field $\mathrm{H}_{2}$-ICWC ${ }^{\mathrm{III}}$ with turbo-pumping on naturally D2 preloaded ILW. Throughout the text the experiments are labeled by superscripts I, II \& III for clarity. The JET ICRF antennas operated in plasma production mode with monopole phasing, coupling 50 to $240 \mathrm{~kW}$ to low density ICRF plasma $0.2-2.4 \times 10^{17} \mathrm{~m}^{-3}$. Preprogrammed gas injection using either a midplane gas injection module located toroidally opposite to the operated ICRF antennas or divertor gas injection modules when operating all 4 antennas simultaneously resulted in discharge pressures of $0.3-7.5 \times 10^{-3} \mathrm{~Pa}$. The turbo and cryo pumping speeds $S$ for $\mathrm{D}_{2}$ and $\mathrm{H}_{2}$ are $S_{\mathrm{D} 2 \text {,turbo }}=6.0 \mathrm{~m}^{3} / \mathrm{s}, S_{\mathrm{H} 2 \text {, turbo }}=5.8 \mathrm{~m}^{3} / \mathrm{s}, S_{\mathrm{D} 2 \text {, cryo }}=$ $115 \mathrm{~m}^{3} / \mathrm{s}$ and, above a pressure of $\sim 10^{-3} \mathrm{~Pa}, S_{\mathrm{H} 2, \text { cryo }}=90 \mathrm{~m}^{3} / \mathrm{s}$. Table 1 summarizes the discharge parameters.

Particle balances are obtained via (i) pressure recordings in the gas injection modules, (ii) risidual gas analysis using (iia) pulse based mass spectrometry and penning gauge spectroscopy in ducts connected to the divertor, and (iib) gas chromatography of the total amount of pumped gas after each of the experiments, ${ }^{\mathrm{I}, \mathrm{II}, \mathrm{III}}$. The evolution of the wall isotopic ratio is indirectly monitored via the plasma isotopic ratio from $\mathrm{H}$ and $\mathrm{D}$ Balmer-beta radiation in the low temperature plasma.

The plasma and wall flux characterization in this paper relies on (i) radial HCN interferometry viewing lines with approximated integration path of $1.4 \mathrm{~m}$, (ii) low energy neutral particle analyser (NPA) measuring the energetic charge exchange (CX) neutral spectral flux (5$50 \mathrm{keV}$ ) along a radial line of sight (iii) penning gauge pressures and (iv) RF signals for 
coupled power calculation. Experimental data are complemented by OD plasma modelling (TOMATOR code [7]) solving energy and particle balance equations for hydrogen atomic and molecular plasma species, taking into account (1) elementary atomic and molecular collision processes, (2) RF heating of electrons and protons, (3) particle and energy confinement, as well as (4) wall flux recycling, active pumping and gas injection.

\section{Discharge characterization}

\subsection{Plasma density}

Pulse averaged interferometry densities measured along radial line of sight for $\mathrm{D}_{2}-\mathrm{ICWC}^{\mathrm{I}}$ on JET-C are shown as function of scaling P. $p^{\mathrm{n}}$ on Fig. 1a, including preparatory pulses excluded from Table 1. Within the pressure $(p)$ and coupled power $(P)$ range of $p=1.0$ to $4.0 \times 10^{-3} \mathrm{~Pa}$ and $P=50$ to $260 \mathrm{~kW}$, the densities vary over 1 order of magnitude from 0.2 to $2.3 \times 10^{17} \mathrm{~m}^{-3}$ and are fitted with good correlation, $\mathrm{R}=0.79$, using power $\mathrm{n}=-1 / 3$. The correlation is calculated as the Pearson coefficient and optimized via regression analysis of the logtransformed data. The density scaling for the same pressure and power range is confirmed by OD ICRF plasma simulations [7] (correlation coefficient $\mathrm{R}>0.99$ ) using fixed coupled power fraction to electrons and atomic ions of resp. 0.9 and 0.1 , based on JET ICWC RF coupling studies [1], and using fixed charged particle confinement time of 5ms. The latter poor confinement is motivated considering the typical simple toroidal magnetic field geometry used for ICWC, characterized by a radial gradient and toroidal curvature, as well as gradients in electron density and temperature which together are know to drive electrostatic instabilities [8]. This enhanced transport (order of magnitude larger than Bohm diffusion) in large devices for the large toroidal field values (1.65-3.3T) combined with low ion and electron temperatures is presently a field of study.

For $\mathrm{D}_{2}$-ICWC ${ }^{\mathrm{II}}$ pulses on JET-ILW, having modest coupled power variations $(140-180 \mathrm{~kW})$, the density of the higher-pressure pulses $\left(2.3 \pm 0.2 \times 10^{-3} \mathrm{~Pa}\right)$ matches the JET-C $\mathrm{C}^{\mathrm{I}}$ fit within a 
factor 1.4. In agreement with numerical simulations for pressures below $0.5 \times 10^{-3} \mathrm{~Pa}$, the remaining pulses at significantly lower pressure $\left(0.5 \pm 0.2 \times 10^{-3} \mathrm{~Pa}\right)$ deviate strongly from the $p^{-1 / 3}$ scaling. The measured density ranges from 2 to $6 \times 10^{16} \mathrm{~m}^{-3}$. Determining the pressuredensity relation for these low density pulses is compromised by drift of the zero-point and low signal to noise ratio in the interferometry data.

No interferometry data was obtained for the $\mathrm{H}_{2}$-ICWC ${ }^{\text {III }}$ pulses. It is expected that the density of these pulses with pressure range of 1.4 to $7.5 \times 10^{-3} \mathrm{~Pa}$ and power range of 100 to $200 \mathrm{~kW}$ can be successfully modeled with the JET-C ${ }^{\mathrm{I}}$-fit, leading to a similar density range of 0.5 to $1.5 \times 10^{17} \mathrm{~m}^{-3}$. It is noted that the likely lower confinement at half field may reduce the values.

\subsection{Wall flux components}

Fundamental in the study of discharge wall conditioning techniques is characterizing the particle fluxes to the vessel first wall. The fluxes discussed in this section will be related to the isotope exchange efficiency in section 4. Simulated for JET-ILW $\mathrm{H}_{2}$-ICWC ${ }^{\text {III }}$ pulses, using the simulation parameters from the previous paragraph, one distinguishes (i) a low energy hydrogen atom flux of 1 to $5 \times 10^{20} / \mathrm{m}^{2} \mathrm{~s}$ with energies between 3 and $5 \mathrm{eV}$ determined by Franck Condon energy upon dissociation and increased by elastic collisions with ions, and a (ii) low energy (atomic) hydrogen ion flux of 0.5 to $2.5 \times 10^{19} / \mathrm{m}^{2} \mathrm{~s}$. It is expected that the high neutral flux enhances surface recombination and hence wall desorption. As neutrals are not constrained by the magnetic field, the neutral flux can be considered homogeneous, reaching also remote areas. For the ion flux it was shown that sheaths affect the ion impact energy on the wall to about $10-50 \mathrm{eV}$ [9]. As ions are transported along the magnetic field lines, the ion flux on JET is likely inhomogeneous, being highest on first limiting surfaces such as antenna protection limiters and inner bumpers. On ITER, designed with a shaped first wall, the ICWC ion-wetted area approaches the total surface area. 
The simulated low energy ion wall flux for JET is found to scale as $P . p^{-1 / 3}(\mathrm{R}>0.99)$ and is thus directly proportional to the electron density, which is understood from the chosen fixed charged particle confinement time. The simulated low energy neutral atom flux on the other hand scales as $P \cdot p^{+1 / 3}(\mathrm{R}>0.99)$, which is proportional to $n_{\mathrm{e}} \cdot p^{+2 / 3}$.

A third wall flux component consists of (iii) energetic neutrals stemming from CX reactions with the minor energetic plasma ion population $(>1 \mathrm{keV})$ produced by resonant ICRF absorption. The fast CX flux measured by NPA on JET is of the order of $1 \times 10^{15}$ to 1 $\mathrm{x} 10^{17} / \mathrm{m}^{2} \mathrm{~s}$ with Maxwellian energies of 1 to $10 \mathrm{keV}$. While the high CX flux energies are sufficient to reach deeper surface layers and to cause physical sputtering, the flux was shown previously to have limited conditioning contribution in JET isotopic exchange ICWC discharges [6]. Energetic ion species produced by local resonant absorption are not described in the $0 \mathrm{D}$ plasma model. Wall flux energies below $1 \mathrm{keV}$ remain presently undiagnosed on JET and require further study.

\section{Isotope exchange efficiency}

\subsection{Particle balance}

Table 1 summarizes the particle balances as obtained from gas injection data and chromatography analysis of the total pumped amount of gas. Within the limited number of RF pulses for $\mathrm{D}_{2}$-ICWC ${ }^{\mathrm{I}}$ on JET-C it was possible to remove $1.6 \times 10^{22}$ hydrogen particles (= about $6 \mathrm{H}$ monolayers) from the GDC preloaded wall, corresponding to approximately $10 \%$ of the short term retention in JET-C accessible by plasma operation $\left(2 \times 10^{23}\right.$ atoms, [10]). For JET-ILW, thought to have a smaller accessible fuel reservoir in tokamak discharges than JET$\mathrm{C}\left(<1 \times 10^{23}\right.$ atoms [11]), $\mathrm{D}_{2}-\mathrm{ICWC}^{\mathrm{II}}$ on the $\mathrm{H}_{2}$-GDC preloaded wall removed $2.9 \times 10^{22} \mathrm{H}$ atoms within a similar total RF discharge time. On increasing the RF discharge time to 206s, for $\mathrm{H}_{2}$-ICWC ${ }^{\mathrm{III}}$ on JET-ILW, the amount of recovered atoms from the naturally loaded wall increases accordingly to $6.2 \times 10^{22} \mathrm{D}$ atoms, approaching complete depletion of the wall loaded 
hydrogen isotope. Ideally, not more than one hydrogen isotope replaces each removed isotope from the wall in the process of isotopic exchange. No/limited extra wall retention is observed in the JET-ILW pulses (last row of Table 1), whereas retention was about 3 times larger than removal in JET-C. In section 4.3 the removal efficiencies are studied as a function of discharge parameters. The analysis of retention dependencies is hence limited to the JET-C pulses.

\subsection{Isotopic exchange}

Fig. 2 (left axis) reflects the progressing change-over of the wall isotopic ratio via the plasma isotopic ratio obtained from $\mathrm{H}$ and $\mathrm{D}$ Balmer-beta radiation spectra along a vertical viewing line looking into the divertor. The isotopic ratio is here defined as the relative hydrogen isotope concentration of the injected isotope, $\mathrm{H}$ for $\mathrm{H}_{2}-\mathrm{ICWC}^{\mathrm{III}}$ and $\mathrm{D}$ for $\mathrm{D}_{2}-\mathrm{ICWC} C^{\mathrm{I}, \mathrm{II}}$. A clear difference between JET-C ${ }^{\mathrm{I}}$ and JET-ILW ${ }^{\mathrm{II}, \mathrm{III}}$ pulses is the lower initial plasma isotopic ratio. The initial wall isotopic ratio as sampled via plasma radiation in $\mathrm{D}_{2}$-tokamak discharges after wall pre-loading for JET-ILW ${ }^{\mathrm{III}}$ experiment is less than $2 \%$ on the figure scale. Material dependent fuel recycling properties of the plasma facing components is thought to be the main cause for this difference, e.g. via a higher wall isotope release yield on JET-C ${ }^{\mathrm{I}}$ wall compared to JET-ILW ${ }^{\text {IIIIII }}$. The wall preloading procedure and the ICRF operation (ITER full field) for $\mathrm{D}_{2}$-ICWC on JET-C ${ }^{\mathrm{I}}$ and JET-ILW ${ }^{\mathrm{II}}$ were identical. The different pumping schemes, cryo-

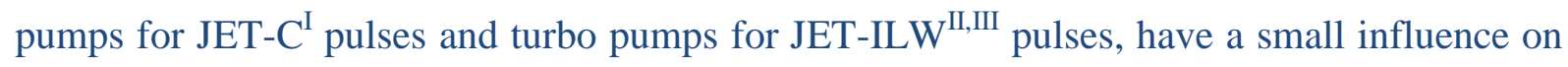
the plasma isotopic ratio as recycling rates are much larger than pumped rates, both for turbo and cryo pumping [12].

Fig. 2 (right axis) shows the cumulated sum of the removed wall isotopes as a function of the total RF time, integrating each time over discharge and post discharge up to the start of the next pulse. It illustrates that the removal (by pumps) is about two times faster for JET-ILW ${ }^{\text {II,III }}$ 
than for JET-C $\mathrm{C}^{\mathrm{I}}$ (see as well Table 1). No clear difference for $\mathrm{D}_{2}-\mathrm{ICWC}^{\mathrm{II}}$ at full field and $\mathrm{H}_{2^{-}}$ ICWC $^{\text {III }}$ at half field appears from these results.

Although the plasma isotopic ratio in JET-ILW ICWC ${ }^{\mathrm{II}, \mathrm{III}}$ remains stable after $\sim 60 \mathrm{~s}$ of discharge time, the cumulated amount of pumped wall isotopes shows no sign of wall isotope depletion yet. The accessible fuel reservoir is clearly larger than the removal achieved within 206s. It is expected that the limits of isotope exchange by ICWC may become clearer on doubling the total discharge time.

\subsection{Parametric dependencies}

a. Removal as function of coupled power, pulse length and wall isotope concentration

Isotope exchange efficiency optimization requires revealing main removal dependencies on discharge parameters. Fig. $1 \mathrm{~b}$ shows for all 3 experiments the removed amount of wall isotopes as function of the product of coupled RF power $P$, pulse length $\Delta t$ and wall isotope concentration $N_{\mathrm{w}}$, reflecting the simple relation $\mathrm{d} N_{\mathrm{w}} / \mathrm{d} t=\mathrm{f}(P, p, \ldots) N_{\mathrm{w}}$. For $\mathrm{D}_{2}$ and $\mathrm{H}_{2}-\mathrm{ICWC}$ on JET-ILW ${ }^{\mathrm{II}, \text { III }}$ the removal is strongly dependent on the loaded wall isotope concentration, significantly changing from pulse to pulse, as well as on the discharge duration $(\mathrm{R}=0.87$ and 0.86 for resp. $\mathrm{D}_{2}{ }^{\mathrm{II}}$ and $\left.\mathrm{H}_{2}{ }^{\mathrm{III}}-\mathrm{ICWC}\right)$. For JET-C ${ }^{\mathrm{I}}$ pulses with constant pulse length and limited wall isotope depletion the dependency is largely determined by the coupled power $(\mathrm{R}=0.90)$. Each of the plots assumes a preset initial accessible wall isotope amount, the accessible reservoir; A correlation above $85 \%$, requires (i) setting the total amount of removed wall isotopes lower than $25 \%$ of the initial concentration for JET-C ${ }^{\mathrm{I}}$ and (ii) a removal of more than $67 \%$ the loaded $\mathrm{H}$ for the $\mathrm{D}_{2}-\mathrm{ICWC}^{\mathrm{II}}$ experiment on JET-ILW. While, for (iii) the $\mathrm{H}_{2^{-}}$ ICWC $^{\mathrm{III}}$ pulses on JET-ILW the optimal correlation is 0.85 when assuming that $85 \%$ of the initial D is removed. The latter experiment ${ }^{\mathrm{III}}$, with $6.2 \times 10^{22}$ recovered wall isotopes (Table 1), indicates an accessible reservoir by ICWC of $7.3 \times 10^{22}$ hydrogen isotopes.

b. Removal as function of density and pressure 
Fig 1c studies the wall isotope removal per ICWC discharge as function of density for the higher-pressure pulse sets $\left(\mathrm{D}_{2}-\mathrm{ICWC}^{\mathrm{I}}\right.$ on JET-C and $\mathrm{H}_{2}$-ICWC ${ }^{\mathrm{III}}$ on JET-ILW). These pulses respect the common density scaling $\mathrm{n}_{\mathrm{e}} \sim P . p^{-1 / 3}$ defined for pressures above $1 \times 10^{-3} \mathrm{~Pa}$ (section 3.1). For the $\mathrm{D}_{2}-\mathrm{ICWC}^{\mathrm{I}}$ pulses on JET-C removal correlates maximally $(\mathrm{R}=0.93)$ with the square root of the density. Verifying with $\mathrm{H}_{2}$-ICWC ${ }^{\text {III }}$ on JET-ILW, plotting removal as function of $\operatorname{sqrt}\left(n_{\mathrm{e}}\right) \cdot \Delta t \cdot N_{\mathrm{w}}$ (Fig. 1c) correcting a such for the varying pulse length and wall isotope concentration in this experiment, as well a good correlation is obtained $(\mathrm{R}=0.80)$. The removal dependency on density indicates that the ion flux delivers an important contribution in wall conditioning by ICWC; the estimated ion flux for the JET ICWC discharges was found to be directly proportional to the density (section 3.2). The higher low-energy neutral flux does not correlate to the isotope removal per pulse as it features an additional strong pressure dependency.

\section{c. Retention on JET-C}

Due to absence of or limited additional retention no clear parametric retention dependencies were found for JET-ILW ICWC ${ }^{\mathrm{II}, I I I}$ pulses. Net retention is here defined as the amount of retained discharge gas minus the amount of recovered wall isotopes. In agreement with observations on C-TORE SUPRA and TEXTOR [13], the on JET-C observed net-retention seems mainly due to an initially incomplete loading of the transient (accessible) reservoir, which is typically observed in first of series ICWC discharges. The net retention per pulse being strongly proportional to the (inverse of the) wall loading $(\mathrm{R}>0.90)$, no clear dependencies on power, density nor pressure were found. The discharge length for each of these JET-C ICWC ${ }^{\mathrm{I}}$ pulses was approximately constant. Modelling of the partial pressures in C-TORE SUPRA ICWC discharges discussed in [14] learned that most of the wall flux is transiently stored, remaining accessible, while a small part is stored permanently (e.g. by 
codeposition with $\mathrm{C}$ in remote areas) which in the continuous fast process of particle recycling leads to significant net retention.

\section{Discussion and conclusions}

JET ICWC discharges, reliably produced at ITER half ${ }^{\mathrm{III}}$ and full field ${ }^{\mathrm{I}, \mathrm{II}}$ conditions, have shown the ability to change the wall isotopic ratio of JET-C ${ }^{\mathrm{I}}$ and JET-ILW ${ }^{\mathrm{II}, \mathrm{III}}$ within limited number of discharges. The presented analysis based on complementing experimental data with OD discharge modeling concludes that for maximizing the wall isotope removal per ICWC discharge one has to aim at long pulses with high RF power, $240 \mathrm{~kW}$ coupled on JET. For pressures above $1 \times 10^{-3} \mathrm{~Pa}$, the removal efficiency reduces with increasing pressure. Besides the improved ICWC isotope exchange rate on ILW ${ }^{\mathrm{II}, I I I}$ providing a cleaner plasma faster, the main advantage compared to $\mathrm{CFC}^{\mathrm{I}}$ is a reduction of the ratio of retained discharge gas to removed wall isotopes, equal to $\sim 3$ for $\mathrm{C}_{\text {-wall }}{ }^{\mathrm{I}}$ and $0.86-1.4$ for the $\mathrm{ILW}^{\mathrm{II}, \mathrm{III}}$. Net fuel retention needs to be avoided in wall conditioning as it may be governed by permanent retention by codeposition in remote areas. As most of the isotopes are recovered in the post discharge phase (high outgassing pressure peak followed by a slow pressure decay [15]), duty cycle optimization studies for ICWC on JET-ILW still need further consideration.

The accessible fuel reservoir by $\mathrm{H}_{2}$-ICWC on JET-ILW ${ }^{\mathrm{III}}$ preloaded by $\mathrm{D}_{2}$ tokamak operation is estimated to be $7.3 \times 10^{22}$ hydrogenic atoms. This number is $\sim 2 \mathrm{x}$ larger than presently achieved in isotope exchange experiments by limiter plasmas [9]. The certainty of the parametric dependencies at base of the ICWC estimations has to be improved via further experimentation, though a close to complete isotopic change over of the reservoirs accessible by ICWC may be expected after 400s of cumulated ICWC discharge time.

The high removal without net retention on JET-ILW indicates that the ICWC wall fluxes in the presented experiments ${ }^{\text {IIIIII }}$ feature inefficient beryllium erosion and redeposition in contrast to limiter plasmas [9]. The fuel inventory of beryllium deposits, predominantly located on 
main wall and at the top of the inner divertor [16], may be accessed. Possibility of complementing limiter plasmas with ICWC for fuel recovery after D:T pulses on ITER requires further investigation.

Further ICWC studies on JET-ILW should envisage (i) increased plasma exposure time of PFC, (ii) determining the dominating plasma wall interaction areas, which are at present most likely the berillium main wall, (iii) increasing the accessible reservoir by discharge homogeneization and (iv) diagnosing the lower energetic ion population $(<1 \mathrm{keV})$.

\section{Acknowledgements}

This work was supported by EURATOM and carried out within the framework of the European Fusion Development Agreement. The views and opinions expressed herein do not necessarily reflect those of the European Commission.

\section{References}

[1] A Lyssoivan et al, Plasma Phys. Control. Fusion 54 (2012) 074014

[2] T Wauters et al, Nucl. Fusion 53 (2013) 123001 (6pp)

[3] D Douai et al, (2012) 24rd IAEA Fusion Energy Conf. (San Diego, USA) Paper EX/P5-09

[4] M Matthews et al, J. Nucl. Mat. 438 (2013) S2-S10

[5] S Brezinsek et al, Nucl. Fusion 53 (2013) 083023 (13pp)

[6] D Douai et al, J. Nucl. Mat. 415 (2011) S1021-S1028

[7] T Wauters et al, Plasma Phys. Control. Fusion 53 (2011) 125003

[8] F Poli et al, Physics of Plasmas 14 (2007) 052311

[9] S Möller et al, J. Nucl. Mat. Xxx, this conference

[10] T. Loarer et al, J. Nucl. Mat. 337-339 (2005) 624-628 


\section{P-1.055}

[11] T. Loarer et al, J. Nucl. Mat. Xxx, this conference

[12] T Wauters et al, J. Nucl. Mat. 415 (2011) S1033-S1036

[13] T Wauters, (2011) Study and optimization of magnetized ICRF discharges for tokamak wall conditioning and assessment of the applicability to ITER, PhD Thesis Ghent University, https://biblio.ugent.be/publication/1978443

[14] D Douai et al, AIP Conf. Proc. 1406 (2011) 191

[15] V Philipps et al, J. Nucl. Mat. 438 (2013) S1067-S1071

[16] A Widdowson et al, Phys. Scr. T159 (2014) 014010 


\section{Figure and Table captions}

Table 1

Overview experimental conditions and particle balance for three JET ICWC isotopic exchange experiments, labelled I, II and III.

\section{Figure 1}

Parametric dependencies for ICWC isotopic exchange discharges on JET-C ${ }^{\mathrm{I}}$ and JET-ILW ${ }^{\mathrm{II}, \mathrm{III}}$ (discharge parameters for labels I, II \& III are given in Table 1, R is the Pearson correlation coefficient).

a) Pulse averaged radial interferometry densities $n_{\mathrm{e}}$ for $\mathrm{D}_{2}-\mathrm{ICWC}$ on JET-C as function of coupled RF power $P$ and pressure $p$, and OD modeled density for pressure and powers of JET-ILW $\mathrm{H}_{2}-\mathrm{ICWC}^{\mathrm{III}}$ pulses. Green: the higher pressure pulses of $\mathrm{D}_{2}-$ ICWC ${ }^{\mathrm{II}} . C$ is a constant.

b) Removed amount of wall isotopes $\Delta N_{\mathrm{w}}$ as function of coupled RF power $P$, pulse length $\Delta t$ and wall isotope concentration $N_{\mathrm{w}}$ for exp. I, II and III.

c) Density dependency of removal for exp. I (left axis) and III (right axis). Densities of III (right axis) are estimated from scaling $P / p^{1 / 3}$.

Figure 2

Isotopic exchange by ICWC as function of cumulated discharge time $(\Sigma \Delta t)$ on JET-C ${ }^{\mathrm{I}}$ and JET-ILW ${ }^{\mathrm{II}, \mathrm{III}}$ (discharge parameters for labels I, II \& III are given in Table 1). Left axis: averaged plasma isotopic ratio $\left(I R_{\mathrm{pl}}\right)$ per discharge obtained from $\mathrm{H}$ and $\mathrm{D}$ beta radiation, defined as $n_{\mathrm{D}} /\left(n_{\mathrm{H}}+n_{\mathrm{D}}\right)$ for case I, II and $n_{\mathrm{H}} /\left(n_{\mathrm{H}}+n_{\mathrm{D}}\right)$ for case III; Right axis: cumulated sum of the removed wall isotopes $\Sigma \Delta N_{\mathrm{w}}$. 
Figures and tables

Table 1

\begin{tabular}{|c|c|c|c|}
\hline & JET-C & JET-ILW & JET-ILW \\
\hline & $\mathrm{D}_{2}-\mathrm{ICWC}^{\mathrm{I}}$ & $\mathrm{D}_{2}$-ICWC & $\mathrm{H}_{2}$-ICWC \\
\hline & $3.3 \mathrm{~T}-25 \mathrm{MHz}$ & $3.3 \mathrm{~T}-25 \mathrm{MHz}$ & $1.65 \mathrm{~T}-25 \mathrm{MHz}$ \\
\hline Vacuum pumping & Cryopumps & Turbopumps & Turbopumps \\
\hline Wall preloading & $\mathrm{H}_{2}-\mathrm{GDC}$ & $\mathrm{H}_{2}-\mathrm{GDC}$ & $\mathrm{D}_{2}$ plasma op. \\
\hline Pressure $\left[\times 10^{-3} \mathrm{~Pa}\right]$ & $1.3-1.6$ & $0.3-2.5$ & $1.4-7.5$ \\
\hline ICRF coup. power [kW] & $50-240$ & $140-180$ & $100-200$ \\
\hline \# pulses, pulse length & $8 \times 8 s$ & $19 \times(2-8) \mathrm{s}$ & $21 \times(2-20) \mathrm{s}$ \\
\hline Total discharge time & $\sim 60 \mathrm{~s}$ & $\sim 65 \mathrm{~s}$ & $\sim 220 \mathrm{~s}$ \\
\hline (a) Recovered atoms $\left(\times 10^{22}\right)$ & $1.6 \mathrm{H}$ & $2.9 \mathrm{H}$ & $6.2 \mathrm{D}$ \\
\hline (b) Retained atoms $\left(\times 10^{22}\right)$ & $4.8 \mathrm{D}$ & $2.5 \mathrm{D}$ & $8.6 \mathrm{H}$ \\
\hline Ratio (b) to (a) & 3.0 & 0.86 & 1.4 \\
\hline
\end{tabular}




\section{P-1.055}

Figure 1
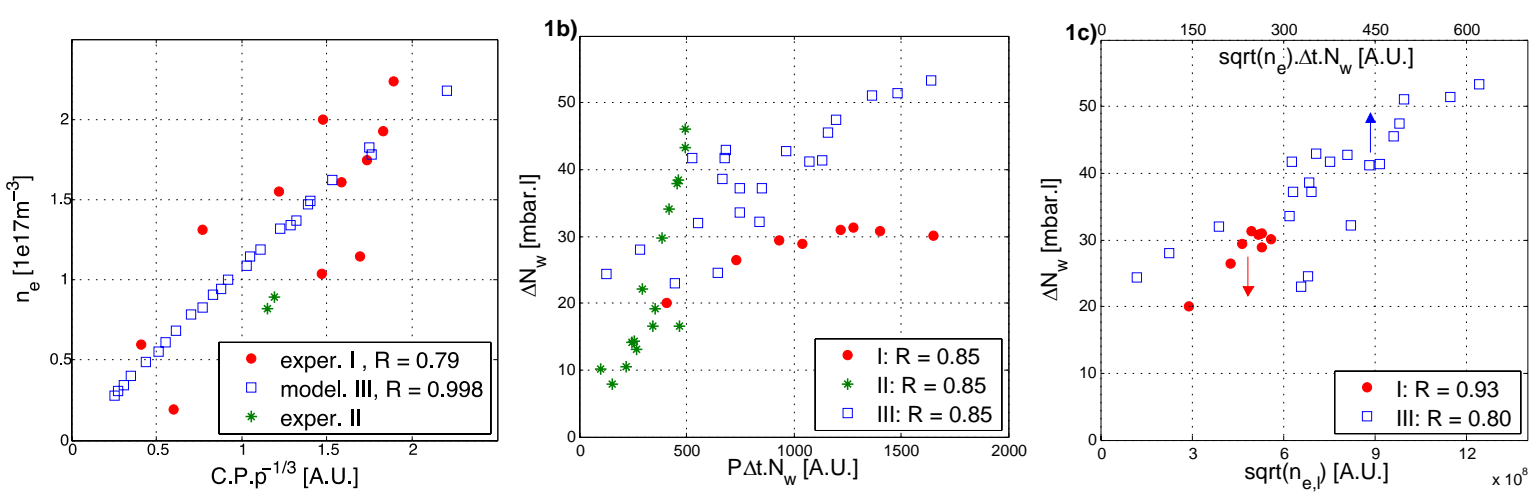


\section{P-1.055}

Figure 2

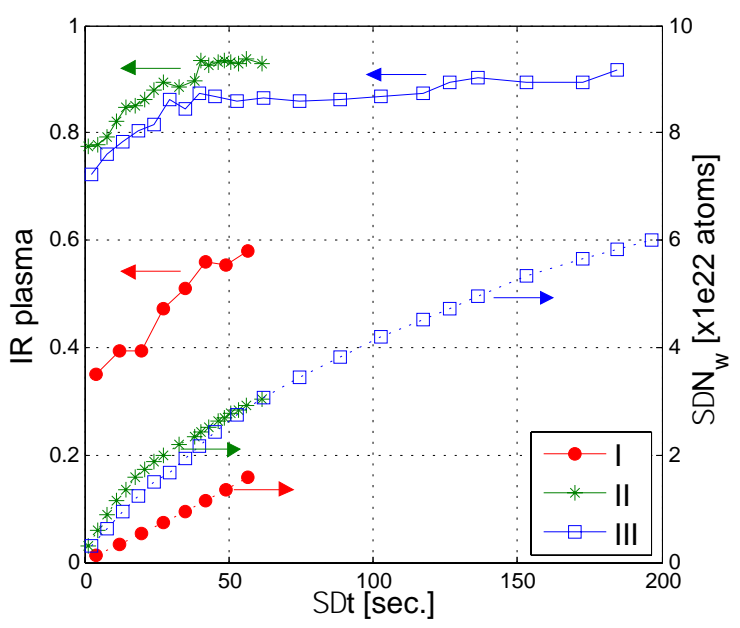

